\title{
INDUÇÃO DO ENRAIZAMENTO E CRESCIMENTO DO EUCALIPTO POR RIZOBACTÉRIAS: EFEITO DA ADIÇÃO DE FONTE ALIMENTAR E DA COMPOSIÇÃO DO SUBSTRATO DE ENRAIZAMENTO'
}

\author{
Reginaldo Gonçalves Mafia ${ }^{2}$, Acelino Couto Alfenas², Eraclides Maria Ferreira², Débora do Amaral \\ Teixeira² e Edival Ângelo Valverde Zauza ${ }^{3}$
}

\begin{abstract}
RESUMO - Neste trabalho, objetivou-se avaliar o efeito de leite em pó como fonte alimentar e do tipo de substrato sobre a indução biológica do enraizamento e crescimento de mudas clonais de eucalipto por isolados de rizobactérias. Para o primeiro objetivo, após a aplicação dos isolados de rizobactérias, na proporção de $0,2 \mathrm{ml} / \mathrm{cc}$ de substrato de uma suspensão de inóculo ajustada para $10^{8}$ u.f.c./ml, enriquecidos ou não com leite em pó (1\%), e decorridos 25 dias do estaqueamento de três clones de eucalipto, avaliaram-se a biomassa seca de raízes e o índice de enraizamento de cada combinação isolado-clone. Para o segundo objetivo, 10 isolados, aplicados na mesma proporção e concentração de inóculos citados anteriormente, foram testados em três substratos de enraizamento: vermiculita pura; moinha de carvão + composto de casca de eucalipto + vermiculita (5:3:1); e composto de casca de arroz carbonizada + vermiculita (1:1), em dois ensaios conduzidos com um clone de eucalipto. Os resultados evidenciaram que a aplicação dos isolados promotores de crescimento proporcionou incrementos significativos na velocidade e índice de enraizamento, bem como no crescimento, expresso pela biomassa radicular, cujos ganhos foram superiores, na aplicação com veiculação da fonte alimentar inicial. Dentre os isolados testados, S1 e 3918 (ambos Bacillus subtilis) foram os mais efetivos para enraizamento e biomassa radicular, com incrementos de 40,6 e 114,2\%, respectivamente. Além disso, não ocorreu interação entre isolados de rizobactérias e substrato de enraizamento, o que permite a utilização desses isolados, independentemente do tipo de substrato empregado.
\end{abstract}

Palavras-chave: Eucalyptus, rizobactérias e substrato.

\section{ROOTING INDUCTION AND GROWTH OF EUCALYPTUS BY RHIZOBACTERIA: EFFECT OF ADDITION OF NUTRIENT SOURCE AND GROWING SUBSTRATE COMPOSITION}

\begin{abstract}
This work aimed to evaluate the effect of powdered milk as a nutrient source and the effect of the substrate composition on the biological rooting induction and minicutting growth by rhizobacteria isolates. A suspension of rhizobacteria $\left(10^{8} \mathrm{cfu} / \mathrm{ml}\right)$ was used to achieve a concentration of $0.2 \mathrm{ml} / \mathrm{cc}$ of substrate with or without powdered milk (1\%). Three eucalyptus clones were transplanted to the treated substrate and 25 days later the root biomass and the rooting index were evaluated. Ten isolates added on the same proportion and concentration were tested in three assays using one eucalyptus clone and two rooting substrates: vermiculite, charcoal powder + eucalyptus rusk compost + vermiculite (5:3:1) and carbonized rice bark + vermiculite (1:1). The results showed that the isolates were effective in increasing the speed and index of rooting as well
\end{abstract}

\footnotetext{
${ }^{1}$ Recebido em 04.01.2006 e aceito para publicação em 29.03.2007.

${ }^{2}$ Departamento de Fitopatologia da Universidade Federal de VIçosa (UFV). Viçosa, MG 36570-000. E-mail:<rgoncalves@ aracruz.com.br>; <aalfenas@ufv.br>; <lamaffia@ufv.br>e<ferreiraem@yahoo.com.br>.

${ }^{3}$ Suzano Papel e Celulose. Itapetininga-SP 18200-000. E-mail: <lsiqueira@ suzano.com.br>.
} 
as the root biomass, whose increases were greater when the nutrient source was applied. Among the isolates tested, S1 and 3912 (both Bacillus subtilis) were the most effective for rooting and root biomass, with increases of 40.6 and $114.2 \%$, respectively. There was no interaction between rhizobacteria isolates and root substrate, which allows using the isolates independently of the substrate.

Keywords: Eucalyptus, rhizobacteria and substrate.

\section{INTRODUÇÃO}

Em virtude da presença de exsudatos radiculares, a rizosfera é uma região de intensa atividade microbiana (BOWEN e ROVIRA, 1999), em que predominam bactérias de vida livre ou associadas aos tecidos vegetais (CHANWAY et al., 1991), que podem apresentar efeitos benéfico, neutro ou deletério às plantas hospedeiras. As bactérias que pertencem ao primeiro grupo têm sido designadas de rizobactérias promotoras do crescimento de plantas (Plant Growth-Promoting Rhizobacteria PGPR) (KLOEPPER e SCHROTH, 1978). Esse termo foi utilizado inicialmente para designar isolados de ocorrência natural de bactérias de vida livre no solo, sendo a maioria pertencente aos gêneros Pseudomonas e Bacillus, que apresentam a capacidade de colonizar as raízes de plantas e estimular o seu crescimento (BENIZRI et al., 2001).

O uso de rizobactérias para promover o incremento na produtividade de plantas tem sido extensivamente estudado nas diversas culturas agronômicas, como batata (BURR et al., 1978; KLOEPPER et al., 1980), canade-açúcar (SUSLOW e SCHROTH, 1982), canola (KLOEPPER et al., 1988), amendoim (TURNER e BACKMAN, 1991), trigo (WELLER e COOK, 1986), cevada (ISWANDI et al., 1987), milho (LALANDE et al., 1989) e tomate (GAGNÉ et al., 1993), entre outras. Todavia, o efeito na produção vegetal em cultivo protegido tem recebido pouca atenção (GAGNÉ et al., 1993).

Os mecanismos de promoção de crescimento por rizobactérias não são totalmente conhecidos, no entanto incluem a habilidade de produzir ou alterar a concentração de reguladores de crescimento, como ácido indolacético, ácido giberélico, citocininas e etileno, fixação assimbiótia de $\mathrm{N}_{2}$, antagonismo contra microrganismos fitopatogênicos, seja por produção de sideróforos, b-1,3 glucanase, quitinases, antibióticos e cianeto, seja por solubilização de fosfato mineral e outros nutrientes (CATTELAN et al., 1999).

R. Árvore, Viçosa-MG, v.31, n.4, p.589-597, 2007
Rizobactérias têm sido utilizadas como inoculantes para biofertilização, biorremediação, biopesticidas e fitoestimulantes. No entanto, o desenvolvimento de produtos comerciais utilizando esse tipo de microrganismo para espécies agronômicas e florestais tem sido um processo lento, em grande parte por variações nas respostas de indução de crescimento após a bacterização (SHISHIDO e CHANWAY, 1998). A fonte dessa variação está relacionada a fatores abióticos e bióticos associados à rizosfera (CHANWAY et al., 1991). Dentre os fatores abióticos, a textura e estrutura do solo relacionada ao conteúdo de nutrientes e umidade, aeração e pH influenciam o crescimento de plantas e microrganismos do solo e intimamente, as respostas de inoculação em mudas com rizobactérias. No entanto, as interações bióticas envolvendo o inóculo da bactéria, a comunidade microbiana natural do solo e o genótipo das plantas hospedeiras têm afetado a magnitude das respostas (CHANWAY et al., 1991). Nesse sentido, acredita-se que a aplicação de isolados selecionados de rizobactérias contendo fonte alimentar inicial pode aumentar a eficiência da microbiolização do substrato, por garantir vantagem competitiva e maior estabilidade nas respostas. Além disso, é importante considerar o possível efeito do tipo de substrato de desenvolvimento das plantas, em função das diferenças quali-quantitativas na comunidade microbiana.

Atualmente, ainda não existem trabalhos sobre a eficiência da aplicação de fontes alimentares sobre a indução de crescimento por rizobactérias. No entanto, sabe-se que diversos produtos alimentares e aditivos de alimentos (leite, lecitina de soja, glutamatos, bicarbonato de sódio, ácido tartárico, ácido fumárico, ácido sórbico, polifosfato de sódio e éster de açúcar, entre outros) têm demonstrado efeito no controle de doenças de plantas. Um dos efeitos indiretos da aplicação desses produtos ocorre via favorecimento da comunidade microbiana antagonista (HAMAN e KRÖMKER, 1997; BETTIOL et al., 1999; ZATARIM et al., 2005). Assim, é possível que o uso desses produtos 
possa favorecer também microrganismos do tipo rizobactérias promotoras do crescimento de plantas, sobretudo no estabelecimento inicial na rizosfera.

Diante dessas hipóteses, este trabalho objetivou avaliar o efeito da adição de fonte alimentar (leite em pó $1 \%$ ) e do tipo de substrato de produção de mudas sobre a indução biológica do enraizamento e crescimento de eucalipto por isolados de rizobactérias.

\section{MATERIAL E MÉTODOS}

\subsection{Isolados de rizobactérias e preparo das suspensões}

Empregaram-se sete isolados de rizobactérias, obtidos a partir da rizosfera de mudas clonais de eucalipto de diferentes regiões do país. Esses microrganismos foram pré-selecionados de acordo com a capacidade em promover incremento na biomassa de raízes e induzir o enraizamento adventício. Empregaram-se os isolados FL1, MF2 e MF4 (Pseudomonas sp.), FL2 (P. aeruginosa), Ca (P. fulva), 3918, S1 e S2 (Bacillus subtilis), R1 (Frateuria aurantia) e CIIb (Stenotrophomonas maltophilia), identificados por meio da análise filogenética de seqüências parciais de DNA ribossomal 16S (rDNA 16S). Os isolados foram depositados na coleção do Laboratório de Patologia Florestal e Genética da Interação Planta-Patógeno (TEIXEIRA, 2001).

Para se proceder ao preparo das suspensões rizobacterianas, cada isolado foi cultivado separadamente em meio de Kado e Heskett (1970) por 48 h, no escuro. Após esse período, procedeu-se à raspagem da massa bacteriana em solução salina $(\mathrm{NaCl} 0,85 \%)$. A concentração das suspensões foram ajustadas de acordo com a correlação entre a densidade ótica e o número de unidades formadoras de colônias (u.f.c./mL) para 0,2 Abs. (540 nm), o que corresponde aproximadamente a $10^{8}$ u.f.c. $/ \mathrm{mL}$. As suspensões foram mantidas sob a refrigeração por no máximo $24 \mathrm{~h}$ antes de sua utilização.

\subsection{Efeito da aplicação de fonte alimentar}

O experimento foi realizado em um viveiro florestal localizado em Teixeira de Freitas, BA, sob condições operacionais de produção. As suspensões de rizobactérias foram previamente enriquecidas com uma fonte alimentar (leite em pó $1 \%$ ) e, em seguida, adicionadas ao substrato de enraizamento constituído de casca de arroz carbonizada, substrato agrícola PlantmaxÒ e vermiculita de granulometria fina (200 L : $50 \mathrm{~kg}: 200$ L), na proporção de $0,1 \mathrm{~mL} / \mathrm{cc}$ de substrato, seguida de homogeneização em misturador apropriado. O substrato de enraizamento foi posteriormente enriquecido com OsmocoteÒ (NPK = 19:06:10) na proporção de $1,37 \mathrm{~g} / \mathrm{L}$ de substrato. Após essa etapa, miniestacas de três clones de eucalipto (clones comerciais híbridos de E. grandis Hill ex Maiden x E. urophylla Blake) foram postas para enraizar no substrato tratado com os isolados de rizobactérias em recipientes do tipo tubetes $(50 \mathrm{cc})$, no interior de casa de enraizamento dotada de nebulização intermitente, temperatura de aproximadamente $28 \pm 5^{\circ} \mathrm{C}$ e umidade relativa do ar acima de $80 \%$. Decorridos 25 dias do estaqueamento, avaliaram-se a biomassa seca de raízes e o índice de enraizamento para cada combinação isolado-clone. Para isso, considerando cada parcela, determinou-se o número de miniestacas enraizadas em relação ao total estaqueado e, após a remoção dos resíduos de substrato e separação da parte aérea do sistema radicular, procedeu-se à secagem das raízes em estufa a $70^{\circ} \mathrm{C}$, por $24-48 \mathrm{~h}$. Após atingir massa constante, determinou-se a biomassa radicular $(\mathrm{mg})$ por miniestaca enraizada.

\subsection{Eficácia dos isolados em diferentes substratos de enraizamento}

Os experimentos foram realizados em um viveiro florestal localizado em Belo Oriente, MG, sob condições operacionais de produção. As suspensões de inóculo de cada um dos 10 isolados de rizobactérias foram utilizadas para o tratamento de três substratos de enraizamento, constituídos de vermiculita pura; moinha de carvão (carvão triturado) + casca de eucalipto (após decomposição) + vermiculita $(5: 3: 1)$ e casca de arroz carbonizada + vermiculita (1:1). O preparo das suspensões bacterianas e o tratamento dos substratos ocorreram conforme a metodologia descrita anteriormente. Após essa etapa, miniestacas com cerca de oito dias de idade de um clone híbrido de E. grandis, após o tratamento de sua base com solução de AIB (Ácido indol-butírico) na concentração de 2.000 ppm, foram postas para enraizar nos respectivos substratos. Decorridos 35 dias em casa de enraizamento, nas mesmas condições descritas previamente, avaliaram-se a porcentagem média de enraizamento e a biomassa do sistema radicular seco. O experimento foi repetido no tempo por duas vezes, para confirmação dos resultados.

\subsection{Análises estatísticas}

O experimento para avaliar o efeito da adição de fonte alimentar foi montado em arranjo fatorial, constituído de quatro isolados e dois tratamentos (com ou sem

R. Árvore, Viçosa-MG, v.31, n.4, p.589-597, 2007 
fonte alimentar) em delineamento inteiramente casualizado, composto de seis parcelas, cada uma constituída de 176 miniestacas. Os dados foram submetidos à análise de variância (ANOVA), aplicandose o teste $\mathrm{F}$ a $5 \%$ de probabilidade, e, posteriormente, procedeu-se às comparações estatísticas utilizando a análise de contrastes.

Na segunda etapa, em que se avaliou o efeito do tipo de substrato, adotou-se o mesmo procedimento descrito anteriormente. Todavia, as comparações das médias dos tratamentos foram realizadas pelo teste de Scott-Knott, a 5\% de significância nos dois ensaios (repetição no tempo). As análises estatísticas foram realizadas com o auxílio do programa estatístico SAEG (EUCLYDES, 1993).

\section{RESULTADOS}

No ensaio realizado para avaliar a influência da adição de fonte alimentar, no índice de enraizamento observou-se efeito significativo somente do clone A (Quadro 1), não sendo constado em qualquer combinação isolado-clone, com ou sem adição de fonte alimentar, efeito deletério sobre o enraizamento. Ademais, para esse clone se constatou maior enraizamento no substrato tratado com rizobactérias, com incremento de $26 \%$, em comparação com o substrato sem microbiolização com rizobactérias.

Em relação ao crescimento, expresso pela biomassa radicular, independentemente do isolado de rizobactéria utilizado, observou-se ganhos de 246, 157 e $214 \%$ nos clones A, B e C, respectivamente, quando se comparou o desenvolvimento do sistema radicular em substrato tratado com rizobactérias em relação à testemunha. A adição de fonte alimentar aumentou o ganho em crescimento do clone A, com incremento de $70 \%$. Em contrapartida, nos demais materiais genéticos testados não se constatou efeito significativo da adição de fonte alimentar (Quadro 1).

Nos dois ensaios realizados para avaliar o efeito do tipo de substrato sobre a indução do enraizamento e crescimento por isolados de rizobactérias, não se observou interação significativa entre isolados e substratos testados. Observou-se, no entanto, efeito de isolados (Figura 1) e de substrato (Figura 2), quando se avaliou o índice de enraizamento, sendo constatado resultado similar, independentemente do substrato utilizado. Entre os isolados testados no primeiro ensaio, FL2, S2, Ca e CIIb foram os melhores tratamentos para enraizamento. Em contrapartida, para biomassa radicular não houve diferença entre os tratamentos. No segundo ensaio, todos os isolados de rizobactérias testados promoveram incrementos no índice de enraizaemtno, enquanto na biomassa radicular não houve efeito da aplicação de rizobactérias. Considerando o efeito do substrato, com relação à biomassa radicular a mistura de casca de arroz carbonizada + vermiculita (1:1) destacouse dos demais substratos testados.

\section{DISCUSSÃO}

Isolados de rizobactérias aplicados em substrato de produção de mudas aumentaram o enraizamento e crescimento do eucalipto, quando propagado vegetativamente. Vários trabalhos apontaram o envolvimento de bactérias na promoção do desenvolvimento do sistema radicular de várias culturas. Burns e Schwarz (1996) observaram estímulo do enraizamento adventício em explantes de Pinus elliottii in vitro, produzido por um isolado não identificado de bactéria, propiciando ganhos de 15 a $90 \%$ em relação à testemunha. No entanto, há poucos trabalhos mostrando o efeito de rizobactérias promotoras de crescimento na iniciação e desenvolvimento de raízes adventícias em estacas. Mayak et al. (1997) observaram maior número e comprimento de raízes em estacas de feijão-mungo em condições de laboratório, induzidos por Pseudomonas putida. Nesse sentido, este trabalho é o primeiro a demonstrar o efeito positivo no enraizamento de miniestacas de eucalipto, em condições operacionais de propagação clonal.

O efeito de rizobactérias promotoras do crescimento de plantas tem sido avaliado principalmente em culturas agronômicas (KLOEPPER e SCHROTH, 1978), mas, recentemente, investigações com espécies arbóreas têm evidenciado resultados promissores (CHANWAY, 1997; ENEBAK et al., 1998; SHISHIDO e CHANWAY, 2000). No setor florestal, onde o tempo de rotação é muito longo, a inoculação com rizobactérias geralmente não objetiva aumento direto na produção de madeira. Todavia, as mudas produzidas com rizobactérias podem apresentar maior índice de sobrevivência e estabelecimento mais precoce no campo após o plantio, em função na melhoria da qualidade do sistema radicular. Neste trabalho, ficou demonstrado o efeito benéfico de rizobactérias sobre o crescimento de raízes, o que afeta, sobremaneira, a qualidade das mudas produzidas e, conseqüentemente, o sucesso do plantio. 
Quadro 1 - Enraizamento (\%) médio e biomassa radicular (mg/miniestaca) de clones de eucalipto em substrato tratado com diferentes isolados de rizobactérias, com ou sem adição de leite em pó como fonte alimentar inicial

Table 1 - Average rooting (\%) and root biomass ( $\mathrm{mg} /$ mini-cutting) of eucalyptus clones in substrate treated with different rhizobacteria isolates with or without powdered milk as nutrient source

\begin{tabular}{|c|c|c|c|c|}
\hline \multirow[t]{2}{*}{ Clone } & \multicolumn{2}{|c|}{ Enraizamento } & \multicolumn{2}{|c|}{ Biomassa radicular } \\
\hline & Testemunha & Rizobactérias & Testemunha & Rizobactérias \\
\hline $\mathrm{A}$ & 61 & $77 *$ & 2,24 & $7,75^{*}$ \\
\hline $\mathrm{B}$ & 72 & $85^{\text {ns }}$ & 2,91 & $7,47^{*}$ \\
\hline $\mathrm{C}$ & 81 & $90^{\mathrm{ns}}$ & 3,58 & $11,24 *$ \\
\hline & Sem fonte alimentar & Com fonte alimentar & Sem fonte alimentar & Com fonte alimentar \\
\hline A & 74 & $80 *$ & 5,74 & $9,77^{*}$ \\
\hline $\mathrm{B}$ & 83 & $88^{\text {ns }}$ & 7,35 & $7,60^{\mathrm{ns}}$ \\
\hline $\mathrm{C}$ & 87 & 93 ns & 10,76 & $11,71 \mathrm{~ns}$ \\
\hline
\end{tabular}

$(*)$ e $\left.{ }^{\left({ }^{n s}\right.}\right)$ após o valor da média de cada variável e clone se referem a significativo e não-significativo, pela análise de contraste, a $5 \%$ de probabilidade.
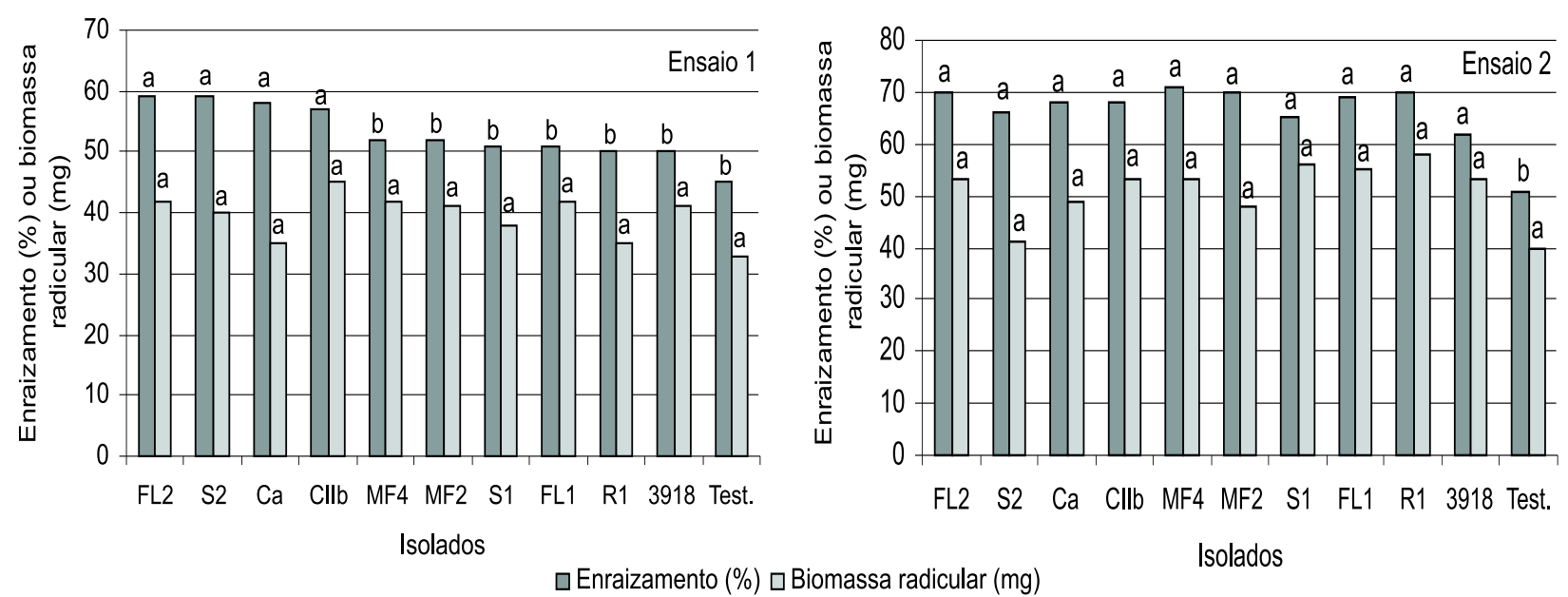

Figura 1 - Enraizamento e biomassa radicular (mg/miniestaca enraizada) de um clone de eucalipto em três substratos de enraizamento (vermiculita pura; moinha de carvão + composto de casca de eucalipto + vermiculita (5:3:2); e composto de casca de arroz carbonizada + vermiculita (1:1)), tratados com 10 isolados de rizobactéria. Médias seguidas pela mesma letra não diferem entre si, pelo teste de Scott-Knott (5\%). CV = 16,7 e 19,3\% (Ensaio 1 ); e $\mathrm{CV}=26,0$ e $22,5 \%$ (Ensaio2), para enraizamento e biomassa radicular, respectivamente.

Figure 1 - Rooting and root biomass ( $\mathrm{mg} / \mathrm{mini}$-cutting) of an eucalyptus clone in three rooting substrates (vermiculite, charcoal powder + eucalypt compost + vermiculite (5:3:1) and carbonized rice rusk + vermiculite (1:1)) treated with 10 rhizobacteria isolates. Columns with the same letter are not significantly different by Scott-Knott test (5\%). $C V=16.7 \%$ and $19.3 \%$ (Essay 1); $C V=26.0 \%$ and $22.5 \%$ (Essay 2), for rooting and root biomass, respectively.

A variabilidade de resposta tem impedido o desenvolvimento de inoculantes bacterianos para espécies arbóreas (CHANWAY e HOLL, 1993, 1994). Pelos resultados, ficou demonstrado que o substrato de enraizamento não interfere nas respostas de microbiolização com rizobactérias. Isso é importante, principalmente quando se considera a aplicação prática de inoculantes, uma vez que, entre diferentes empresas que realizama propagaçãoclonal doeucalipto, existem diferenças quanto ao substrato de produção de mudas. No entanto, parece existir especificidade entre isolados de rizobactérias e clones de eucalipto. Assim, é possível presumir que uma estratégia interessante seria a utilização dos isolados em misturas sabidamente compatíveis, do ponto de vista microbiológico, conforme já é utilizado no biocontrole de patógenos (RAUPACH e KLOEPPER, 1998).

R. Árvore, Viçosa-MG, v.31, n.4, p.589-597, 2007 

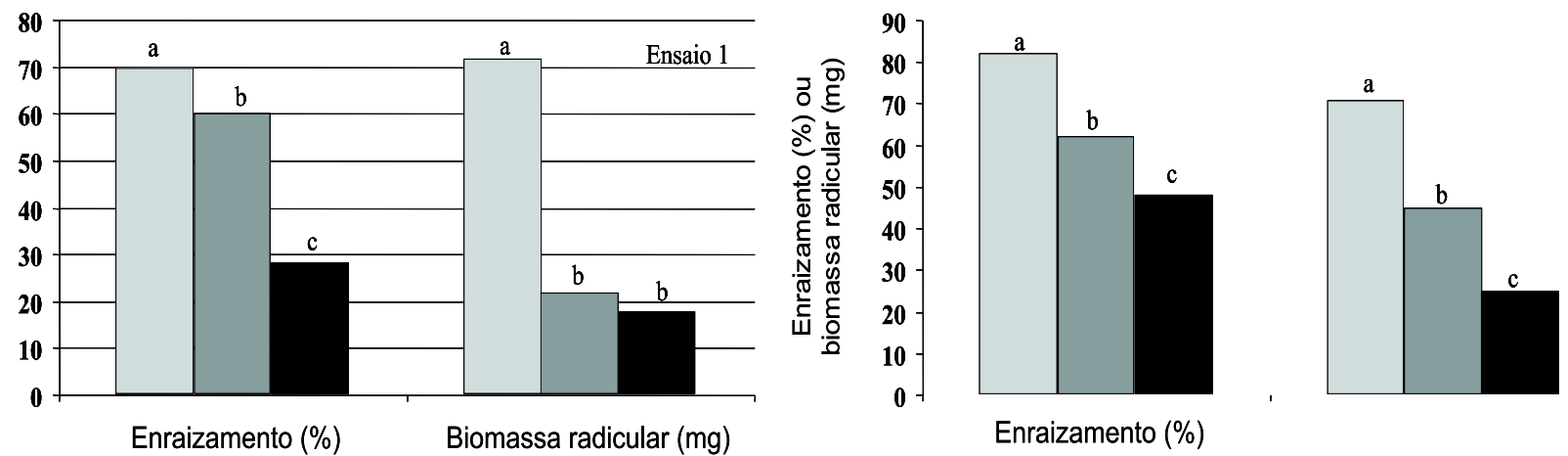

Composto de casca de arroz carbonizada + vermiculita (1:1)

Moinha de carvão + composto de casca de eucalipto + vermiculita (5:3:2)

Figura 2 - Enraizamento e biomassa radicular (mg/miniestaca enraizada) de um clone de eucalipto em três substratos de enraizamento (vermiculita pura; moinha de carvão + composto de casca de eucalipto + vermiculita (5:3:2); e composto de casca de arroz carbonizada + vermiculita (1:1)), tratados com 10 isolados de rizobactéria. Médias seguidas pela mesma letra não diferem entre si, pelo teste de Scott-Knott (5\%). CV = 16,7 e 29,3\% (Ensaio 1 ); $\mathrm{CV}=16,0$ e $36,5 \%$ (Ensaio2), para enraizamento e biomassa radicular, respectivamente.

Figure 2 -Rooting and root biomass ( $\mathrm{mg} /$ mini-cutting) of an eucalyptus clone in three rooting substrates (vermiculite, charcoal residues + eucalypt bark compost + vermiculite $(5: 3: 1)$ and carbonized rice bark + vermiculite (1:1)) treated with 10 rhizobacteria isolates. Columns with the same letter are not significantly different by Scott-Knott test $(5 \%) . C V=16.7 \%$ and $29.3 \%$ (Essay 1); $C V=16.0$ and $36.5 \%$ (Essay 2), for rooting and root biomass, respectively.

Para um clone de eucalipto, entre os três testados foi comprovado o aumento do efeito benéfico com a adição de uma fonte alimentar inicial para as rizobactérias. Acredita-se que, nesse caso, a fonte alimentar possa propiciar maior vantagem competitiva aos isolados de rizobactérias, garantindo maior colonização da rizosfera. A redução na população de certas rizobactérias na rizosfera é apontada como um dos motivos da variabilidade de resposta quanto à indução do crescimento (REDDY e RAHE, 1989; HOLLe CHANWAY, 1992; SHISHIDO et al., 1995). Sabe-se que o leite possui, em sua constituição, sais de $\mathrm{Ca}, \mathrm{Fe}, \mathrm{Mg}$, proteínas, vitaminas, aminoácidos e gorduras, entre outros, que podem favorecer determinados microrganismos, dependendo de suas características metabólicas e bioquímicas (HAMAN e KRÖMKER, 1997; BETTIOL et al., 1999; ZATARIM et al., 2005). Resultados de trabalhos anteriores evidenciaram que o uso dessa fonte alimentar resultou em maior crescimento dos isolados de rizobactérias in vitro (dados não publicados). O uso de uma fonte alimentar inicial pode ser importante para a aplicação dos isolados de rizobactérias in natura, assim como também pode garantir melhores resultados para uma formulação comercial desses microrganismos.

É importante considerar que o efeito da adição da fonte alimentar foi significativo somente nos três clones testados. Nesse caso, é possível supor que, mesmo atendendo aos requerimentos nutricionais das rizobactérias, existe uma limitação quanto à promoção do enraizamento e crescimento ocasionada pelas próprias características do material genético de eucalipto. Dentre os clones de eucalipto testados, o que respondeu à aplicação da fonte alimentar foi o que apresentou menores médias das variáveis enraizamento e biomassa radicular sem aplicação dos isolados de rizobactérias. Nos demais clones, provavelmente a multiplicação vegetativa já ocorre em condições suficientemente favoráveis para a expressão do máximo de enraizamento e crescimento, não sendo, portanto, possível obter ganhos com o processo de aplicação de rizobactérias no substrato de produção de mudas.

A inoculação de mudas no viveiro e antes do plantio pode aumentar a estabilização da comunidade de rizobactérias e sua persistência no campo. Tal fato pode estar relacionado à necessidade de determinado intervalo de tempo para ocorrer a estabilização da população do microrganismo benéfico, especialmente quando este é do tipo endofítico (SHISHIDO e CHANWAY, 2000). Nesse sentido, a estratégia de produção de mudas pelo tratamento do substrato aparentemente constitui 
estratégia vantajosa e com resultados consistentes, de acordo com o observado neste trabalho.

Constatou-se efeito significativo do tipo de substrato usado para produção de mudas de eucalipto. No entanto, não se observou interação entre substratoisolado, o que facilita a utilização desses isolados por várias empresas florestais, que empregam substratos de constituição diferente. Mesmo em um substrato praticamente inerte do ponto de vista biológico, ou seja, em vermiculita pura, observaram-se ganhos decorrentes dos tratamentos com rizobactérias, o que pode ser um indício de envolvimento de mecanismos diretos, provavelmente fitormônios, na promoção de enraizamento. Essa constatação viabiliza a aplicação desses isolados em empresas florestais que utilizem diferentes substratos de enraizamento.

Diante do exposto, a propagação clonal do eucalipto utilizando rizobactérias benéficas pode alcançar elevada produtividade em função do maior índice de enraizamento e crescimento das mudas. Observaram-se, para determinados materiais genéticos, incrementos significativos, principalmente quando o inóculo for enriquecido com uma fonte alimentar, e, não havendo interação entre isolados de rizobactérias e substratos de produção de mudas, a tecnologia poderá ser empregada independentemente do substrato empregado para a produção de mudas de eucalipto.

\section{CONCLUSÕES}

Os resultados deste trabalho permitem a conclusão de que:

$>$ A aplicação de isolados de rizobactérias no substrato de produção de mudas aumentou o enraizamento e crescimento das mudas, cujos incrementos variaram conforme o clone de eucalipto e isolado de rizobactéria testados.

$>$ A adição de fonte alimentar (leite em pó 1\%) resultou em melhor efeito da aplicação dos isolados de rizobactérias, dependendo do clone de eucalipto.

Não houve efeito do tipo de substrato de produção de mudas sobre as respostas ao processo de indução do enraizamento e crescimento de mudas de eucalipto mediado por isolados de rizobactérias.

\section{AGRADECIMENTOS}

Às empresas florestais Aracruz Celulose S.A., CAF Santa Bárbara Ltda., Cenibra S.A., International Paper do Brasil, Jari Celulose S.A., Lwarcel Celulose e Papel Ltda., Plantar S.A., Cia. Suzano Bahia Sul Celulose S.A. e Veracel Celulose S.A., pelo apoio logístico e financiamento.

\section{REFERÊNCIAS}

BENIZRI, E.; BAUDOIN, E.; GUCKERT, A. Root colonization by inoculated plant growthpromoting rhizobacteria. Biocontrol Science and Technology, v.11, p.557-574, 2001.

BETTIOL, W.; ASTIARRAGA, B. D.; LUIZ, A. J. B. Effectiveness of cow's milk against zucchini squash powdery mildew (Sphaeroteca fuliginea) in greenhouse conditions. Crop Protection, v.18, p.489-492, 1999.

BOWEN, G. D.; ROVIRA, A. D. The rhizosphere and its management to improve plant growth.

Advances in Agronomy, v.66, p.1-12, 1999.

BURNS, J. A.; SCHWARS, O. J. Bacterial stimulation of adventitious rooting on in vitro cultured slash pine seedling explants. Plant Cell Reports, v.15, p.405-408, 1996.

BURR, T. J.; SCHROTH, M. N.; SUSLOW, T. Increased potato yields by treatment of seedpieces with specific strains of Pseudomonas fluorescens and P. putida. Phytopathology, v.68, p.1377-1383, 1978.

CATTELAN, A. J.; HARTEL, P. G.; FUHRMANN, J. J. Screening for plant growth-promoting rhizobacteria to promote early soybean growth. Soil Science Society of America Journal, v.63, p.1670-1680, 1999.

CHANWAY, C. P. Inoculation of tree roots with plant growth promoting soil bacteria: an emerging technology for reforestation. Forest Science, v.43, p.99-112, 1997.

CHANWAY, C. P.; HOLL, F. B. First year field permanence of spruce seedlings inoculated with plant growth promoting rhizobacteria.

Canadian Journal of Microbiology, v.39, p.1084-1088, 1993.

CHANWAY, C. P.; HOLL, F. B. Growth of outplanted lodgepole pine seedlings one year after inoculation with growth promoting rhizobacteria. Forest Science, v.40, p.238-246, 1994.

R. Árvore, Viçosa-MG, v.31, n.4, p.589-597, 2007 
CHANWAY, C. P.; TURKINGTON, R.; HOLL, F. B. Ecological implications of specificity between plants and rhizosphere microorganisms. Advances in Ecological Research, v.21, p.121-169, 1991.

ENEBAK, S. A.; WEI, G.; KLOEPPER, J. W. Effects of plant growth-promoting rhizobacteria on loblolly and slash pine seedlings. Forest Science, v.44, p.139-144, 1998.

EUCLYDES, R. F. Manual de utilização do programa SAEG (Sistema para Análises Estatística e Genética). Viçosa, MG: Universidade Federal de Viçosa, 1993. 59p.

GAGNÉ, S. et al. Increase of greenhouse tomato fruit yields by plant growth-promoting rhizobacteria (PGPR) inoculated into the peatbased growing media. Soil Biology and Biochemistry, v.25, p.269-272, 1993.

HAMANN, J.; KRÖMKER, V. Potential of specific milk composition variables for cow health management. Livestock Production Science, v.48, p.201-208, 1997.

HOLL, F. B.; CHANWAY, C. P. Rhizosphere colonization and seedling growth promotion of lodgepole pine by Bacillus polymyxa.

Canadian Journal of Microbiology, v.38, p.303-308, 1992.

ISWANDI, A. et al. Effect of the seed inoculation with the rhizopseudomonad strains 7 NSK 2 on the root microbiota of maize (Zea mays) and barley (Hordeum vulgare). Biology and Fertility of Soils, v.3, p.153-158, 1987.

KLOEPPER, J. W. et al. Plant growth-promoting rhizobacteria on canola (rape-seed). Plant Disease, v.72, p.42-46, 1988.

KLOEPPER, J. W.; SCHROTH, M. M. Plant growth promoting rhizobacteria on radishes. In: INTERNATIONALCONFERENCE ON PLANT PATHOGENIC BACTERIA, 4., 1978, Angers. Proceedings... Angers, France, 1978. p.879-882.

KLOEPPER, J. W.; SCHROTH, M. N.; MILLER, T. D. Effects of rhizosphere colonization by plant growth-promoting rhizobacteria on potato plant development and yield. Phytopathology, v.70, p.1078-1082, 1980.

R. Árvore, Viçosa-MG, v.31, n.4, p.589-597, 2007
LALANDE, R. et al. Identification of rhizobacteria from maize and determination of their plantgrowth promoting potential. Plant and Soil, v.115, p.7-11, 1989.

MAYAK, S.; TIROSH, T.; GLICK, B.R. The influence of plant griwth promoting rhizobacterium Pseudomonas putida GR12-2 on the rooting of mung bean cuttings. In: INTERNATIONAL WORKSHOPON PLANTGROWTH-PROMOTING RHIZOBACTERIA, 4, 1997, Sapporo- Japan. Proceedings... SapporoJapan: 1997. p.313-315.

RAUPACH, G. S.; KLOEPPER, J. W. Mixtures of plant growth-promoting rhizobacteria enhance biological control of multiple cucumber pathogens. Phytopathology, v.88, p.1158-1164, 1998.

REDDY, M. S.; RAHE, J. E. Growth effects associated with seed bacterization not correlated with populations of Bacillus subtilis inoculant in orion seedling rhizospheres. Soil Biology and Biochemistry, v.21, p.373-378, 1989.

SHISHIDO, M.; CHANWAY, C. P. Colonization and growth promotion of outplanted spruce seedlings pré-inoculated with plant growthpromoting rhizobacteria in the greenhouse. Canadian Journal Forest Research, v.30, p.845-854, 2000.

SHISHIDO, M.; CHANWAY, C. P. Storage effects on indigenous soil microbial communities and PGPR efficacy. Soil Biology and Biochemistry, v.7, p.939-947, 1998.

SHISHIDO, M.; LOEB, B. M.; CHANWAY, C. P. Rhizosphere and internal root colonization of lodgepole pine by two seedling growth-promoting Bacillus strains originating from different root microsites. Canadian Journal of Microbiology, v.41, p. 701-713, 1995.

SUSLOW, T. V.; SCHROTH, M. N. Rhizobacteria of sugarbeet: effects of seed application and root colonization on yield. Phytopathology, v.72, p.199-206, 1982. 
TEIXEIRA, D. A. Promoção de enraizamento e indução de resistência sistêmica à ferrugem e à mancha-deCylindrocladium, mediadas por rizobactérias em clones de Eucalyptus spp. 2001. 67f. Tese (Doutorado em Fitopatologia) Universidade Federal de Viçosa, Viçosa, MG, 2001.

TURNER, J. T.; BACKMAN, P. A. Factors relating to peanut yield increases after seed treatment with Bacillus subtilis. Plant Disease, v.75, p.347-353, 1991.
WELLER, D. M.; COOK, R. J. Increased growth of wheat by seed treatments with fluorescent pseudomanads, and implications of Pythium control. Canadian Journal of Plant Pathology, v.8, p.328-334, 1986.

ZATARIM, M.; CARDOSO, A. I. I.;

FURTADO, E. L. Efeito de tipos de leite sobre oídio e abóbora plantadas a campo. Horticultura Brasileira, v.23, p.198-201, 2005. 
